\title{
New Kinetic Spectrophotometric Method for Determination of Atorvastatin in Pure and Pharmaceutical Dosage Forms
}

\section{Safwan Ashour*}

Analytical Biochemistry Laboratory, Department of Chemistry, Faculty of Sciences, University of Aleppo, Aleppo, Syria

\begin{abstract}
New, accurate, sensitive and reliable kinetic spectrophotometric method for the assay of atorvastatin calcium (AVS) in pure form and pharmaceutical formulations has been developed. The method involves the oxidative coupling reaction of AVS with 3-methyl-2-benzothiazolinone hydrazone hydrochloride monohydrate (MBTH) in the presence of $\mathrm{Ce}(\mathrm{IV})$ in an acidic medium to form colored product with lambdamax at $566 \mathrm{~nm}$. The reaction is followed spectrophotometrically by measuring the increase in absorbance at $566 \mathrm{~nm}$ as a function of time. The initial rate and fixed time methods were adopted for constructing the calibration curves. The linearity range was found to be 2.0-20.0 $\mu \mathrm{g} / \mathrm{mL}$ for initial rate and fixed time methods. The limit of detection for initial rate and fixed time methods is 0.093 and $0.064 \mu \mathrm{g} / \mathrm{mL}$, respectively. Molar absorptivity for the method was found to be $3.36 \times 10^{4} \mathrm{~L} / \mathrm{mol} \mathrm{cm}$. Statistical treatment of the experimental results indicates that the methods are precise and accurate. Both methods have been applied successfully for the estimation of pravastatin sodium in commercial dosage forms with no interference from the excipients. The results are compared with the pharmacopoeial method.
\end{abstract}

Keywords: Atorvastatin; Kinetic spectrophotometry; 3-methyl-2benzothiazolinone hydrazone hydrochloride monohydrate $(\mathrm{MBTH})$ and Tablets

\section{Introduction}

Statins are commonly used to treat several forms of hypercholesterolemia. They have potent cholesterol-lowering effects and they could reduce morbidity and mortality associated with coronary heart disease significantly, as proved by many clinical trials. Atorvastatin calcium $\left\{\left[\mathrm{R}-\left(\mathrm{R}, \mathrm{R}^{\star}\right)\right]-2\right.$-(4-flurophenyl)- $\beta, \delta$-dihydroxy5(1-methylethyl)-3-phenyl-4-[phenylamino)carbonyl]-1H-pyrrole1-heptanoic acid, calcium salt (2:1) trihydrate is the most commonly occurring drug in commercially available pharmaceutical formulations used for the clinical treatment of hypercholesterolemia [1]. Several methods have been described for the quantitative determination of atorvastatin by high-performance liquid chromatography (HPLC) in different pharmaceutical preparations, either alone [2-7] or with other active ingredients [8-16]. HPTLC [17], electrochemical $[18,19]$, capillary electrophoresis [20] and spectrofluorimetric [21] methods have been developed for the analysis of atorvastatin from its individual and combined formulations with other active ingredients in pharmaceutical preparations and plasma. Various spectrophotometric methods have been reported for the determination of atorvastatin [8,14,22-26] from its individual and combined formulations with other active ingredients. The official procedures in pharmaceutical preparations utilize non-aqueous titration method [27].

Kinetic methods have certain advantages in pharmaceutical analysis regarding selectivity and elimination of additive interferences, which affect direct spectrophotometeric methods. The literature is still poor in analytical assay methods based on kinetics for the determination of atorvastatin in dosage forms. Some specific advantages that the kinetic methods possess are as follows [28]:

- Simple and fast methods because some experimental steps such as filtration, extraction, etc. are avoided prior to absorbance measurements.

- High selectivity since they involve the measurement of the absorbance as a function of reaction time instead of measuring the concrete absorbance value.
- Other active compounds present in the commercial dosage forms may not interfere if they are resisting the chemical reaction conditions established for the proposed kinetic method.

- Colored and/or turbid sample background may possibly not interfere with the determination process.

Therefore, there is a need for another kinetic approach to estimate the drug in commercial dosage forms. The objective of the present study was to develop a precise, accurate and validated kinetic spectrophotometric method by the application of oxidative coupling reaction for the estimation of AVS in bulk and pharmaceutical formulations.

\section{Materials and Methods}

\section{Apparatus}

A Jasco V-530 UV-VIS spectrophotometer (Japan) with $1 \mathrm{~cm}$ quartz cells was used for all absorbance measurements under the following operating conditions: scan speed medium (400 $\mathrm{nm} / \mathrm{min})$, scan range 400-800 $\mathrm{nm}$ and slit width $2 \mathrm{~nm}$. Spectra were automatically obtained by Jasco system software. A digimed $\mathrm{pH}$ meter (model T-901) with combined glass $\mathrm{pH}$ electrode and a Thornton sonicator (model T-14) were also used.

\section{Chemicals}

Atorvastatin calcium (AVS), $\left(\mathrm{C}_{33} \mathrm{H}_{34} \mathrm{FN}_{2} \mathrm{O}_{5}\right)_{2} \mathrm{Ca} .3 \mathrm{H}_{2} \mathrm{O}, 1209.42 \mathrm{~g} /$ mol, was supplied by CADILA Healthcare Limited (India). Its purity

${ }^{*}$ Corresponding author: Safwan Ashour, Department of Chemistry, Faculty of Sciences, University of Aleppo, Aleppo, Syria, Tel: 009-639-336-040-16; E-mail: profashour2010@myway.com

Received April 01, 2013; Accepted April 20, 2013; Published April 25, 2013

Citation: Ashour S (2013) New Kinetic Spectrophotometric Method for Determination of Atorvastatin in Pure and Pharmaceutical Dosage Forms. Pharm Anal Acta 4: 232. doi:10.4172/2153-2435.1000232

Copyright: ( 2013 Ashour S. This is an open-access article distributed under the terms of the Creative Commons Attribution License, which permits unrestricted use, distribution, and reproduction in any medium, provided the original author and source are credited. 
Citation: Ashour S (2013) New Kinetic Spectrophotometric Method for Determination of Atorvastatin in Pure and Pharmaceutical Dosage Forms. Pharm Anal Acta 4: 232. doi:10.4172/2153-2435.1000232

was found to be $99.5 \%$ according to the official method [27]. All other chemicals and reagents used were of analytical grade and all solutions were prepared with double distilled water.

\section{Formulations}

The following commercial formulations were subjected to the analytical procedures:

1. Atoraz tablets (Razi Labs, Syria) labeled to contain $20 \mathrm{mg}$ atorvastatin /tablet.

2. Low-lip tablets (Al Fares, Syria) labeled to contain $10 \mathrm{mg}$ atorvastatin /tablet.

3. Atorvast tablets (Even Zuher, Syria) labeled to contain $40 \mathrm{mg}$ atorvastatin/tablet.

4. Atorvatin tablets (Alpha, Syria) labeled to contain $20 \mathrm{mg}$ atorvastatin/tablet.

5. Atorvex tablets (Asia, Syria) labeled to contain $80 \mathrm{mg}$ atorvastatin/tablet.

6. Lipolysin tablets (Oubari Pharma, Syria) labeled to contain 20 $\mathrm{mg}$ atorvastatin/tablet.

\section{Solutions}

Stock standard solution of $0.5 \mathrm{mg} / \mathrm{mL}$ was prepared by dissolving the appropriate weight of AVS in $100 \mathrm{~mL}$ volumetric flask, $5 \mathrm{~mL}$ of methanol was added, the volume was then diluted to the mark with distilled water. $1 \times 10^{-2} \mathrm{M}$ 3-methyl-2-benzothiazolinone hydrazone hydrochloride monohydrate $(\mathrm{MBTH})$ (Fluka) solution was prepared with double distilled water and $1 \% \mathrm{Ce}\left(\mathrm{SO}_{4}\right)_{2}$ (Merck) solution was prepared with sulfuric acid $(0.368 \mathrm{M})$ medium. Freshly prepared solutions were always used.

\section{General procedures}

Initial rate method: Aliquots of standard AVS solution (0.1-1.0 $\mathrm{mL}, 0.5 \mathrm{mg} / \mathrm{mL}$ ) were transferred into a series of $25 \mathrm{~mL}$ calibrated volumetric flasks. Then $1.0 \mathrm{~mL}$ of MBTH solution was added and kept aside for $3 \mathrm{~min}$. After that, $1.0 \mathrm{~mL}$ of $\mathrm{Ce}\left(\mathrm{SO}_{4}\right)_{2}$ solution was added. The volume was made up to the mark with distilled water. After mixing, the contents of each flask were immediately transferred to the spectrophotometric cell and the increase in absorbance was recorded at $566 \mathrm{~nm}$ as a function of time between 0-20 min against reagent blank treated similarly. The initial rate of the reaction $(v)$ at different concentrations was obtained from the slope of the tangent to the absorbance-time curve. The calibration curve was constructed by plotting the $\log$ arithm of the initial rate $(\log v) v s$. the logarithm of the molar concentration of the AVS $(\log \mathrm{C})$. The amount of the drug was obtained either from the calibration graphs or the regression equation.

Fixed time method: Aliquots of standard AVS solution (0.1 -1.0 $\mathrm{mL}, 0.5 \mathrm{mg} / \mathrm{mL}$ ) were transferred into a series of $25 \mathrm{~mL}$ calibrated volumetric flasks. Then $1.0 \mathrm{~mL}$ of MBTH solution was added and kept aside for $3 \mathrm{~min}$. After that, $1.0 \mathrm{~mL}$ of $\mathrm{Ce}\left(\mathrm{SO}_{4}\right)_{2}$ solution was added. The volume was made up to the mark with distilled water. After mixing, the absorbance was measured after $800 \mathrm{sec}$ at $566 \mathrm{~nm}$ against reagent blank treated similarly. The calibration curve was constructed by plotting the absorbance against the final concentration of the drug. The amount of the drug in each sample was computed either from calibration curve or regression equation.

\section{Procedures for formulations}

Twenty tablets containing AVS were weighed and pulverized.
An amount of the powder equivalent to $25 \mathrm{mg}$ of the cited drug was dissolved in a $25 \mathrm{~mL}$ of methanol and mixed for about $5 \mathrm{~min}$ and then filtered through Whatman filter paper number 40. The methanol was evaporated to about $5 \mathrm{~mL}$. The remaining portion of solution was diluted in a $50 \mathrm{~mL}$ volumetric flask to the volume with double distilled water to achieve a concentration of $0.5 \mathrm{mg} / \mathrm{mL}$. The general procedure was then followed in the concentration ranges mentioned above.

\section{Results and Discussion}

\section{Absorption spectra}

Atorvastatin reacts with $(\mathrm{MBTH})$ in the presence of $\mathrm{Ce}\left(\mathrm{SO}_{4}\right)_{2}$ in an acidic medium to form pink colored oxidative coupling product that can be measured at $566 \mathrm{~nm}$. Under the experimental conditions the pure drug showed a negligible absorbance at the corresponding maximum (Figure 1). Under the reaction conditions, on oxidation, MBTH loses two electrons and one proton forming an electrophilic intermediate, which is the active coupling species. The coupling of the oxidized form of the drug with electrophilic intermediate of MBTH results in the formation of intensely colored product [26]. The reaction mechanism for the method is shown in scheme 1 .

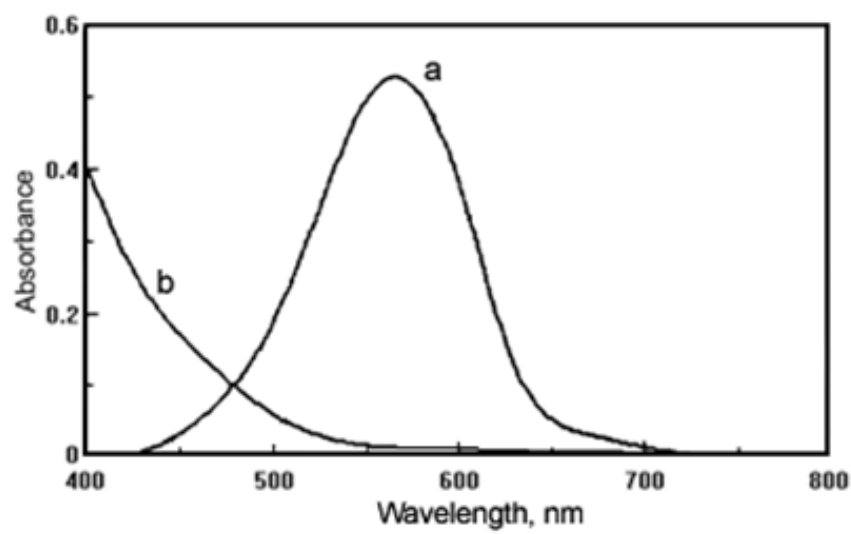

Figure 1: Absorption spectra of (a) AVS-MBTH-Ce( $\left(\mathrm{SO}_{4}\right)_{2}$ system against reagent blank (b) vs. distilled water. $\mathrm{C}_{\mathrm{Avs}}=20 \mu \mathrm{g} / \mathrm{mL}+1 \mathrm{~mL}$ of $10^{-2} \mathrm{M} \mathrm{MBTH}+1$ $\mathrm{mL}$ of $1 \% \mathrm{Ce}\left(\mathrm{SO}_{4}\right)_{2}$
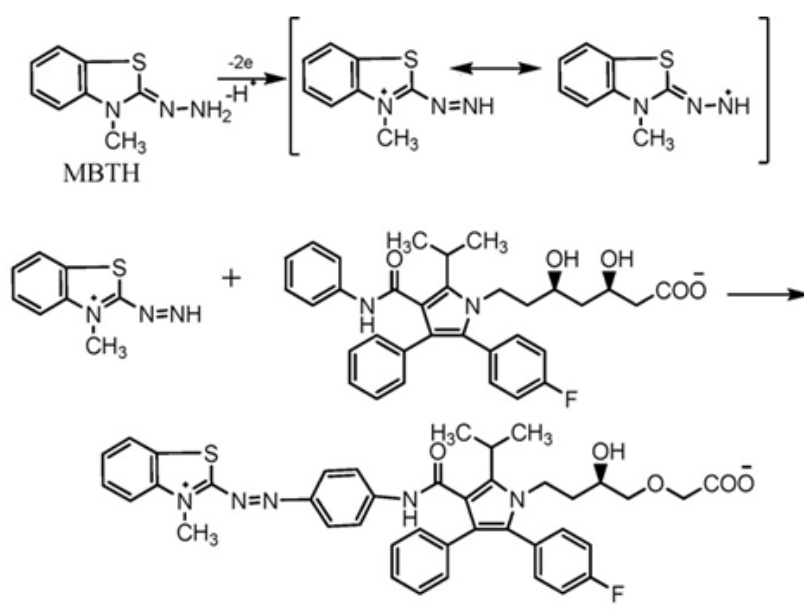

Scheme 1: Structures of AVS and its reaction product with MBTH 
Citation: Ashour S (2013) New Kinetic Spectrophotometric Method for Determination of Atorvastatin in Pure and Pharmaceutical Dosage Forms. Pharm Anal Acta 4: 232. doi:10.4172/2153-2435.1000232

\section{Optimization of reaction conditions}

The development of the color product depends on the reaction conditions and was optimized as follows. The effect of various parameters such as volume of $\mathrm{MBTH}$ and $\mathrm{Ce}\left(\mathrm{SO}_{4}\right)_{2}$, addition of buffer solutions, waiting time, order of addition of reagents and the stability of colored oxidative coupling product were studied at room temperature. The applicability of $\mathrm{MBTH}$ in combination with various oxidizing agents such as $\mathrm{FeCl}_{3}, \mathrm{KIO}_{4}, \mathrm{NaIO}_{4}, \mathrm{Ce}\left(\mathrm{SO}_{4}\right)_{2}, \mathrm{~K}_{2} \mathrm{Cr}_{2} \mathrm{O}_{7}$ and $\mathrm{KMnO}_{4}$ were examined. $\mathrm{Ce}\left(\mathrm{SO}_{4}\right)_{2}$ was found to be optimal to form colored oxidative coupling product (AVS-MBTH) and enhanced the final color. Addition of $\mathrm{KCl}-\mathrm{HCl}$ or Britton buffer solutions effected negativity on the formation of the colored oxidative coupling product. Addition of drug, $\mathrm{MBTH}$ and $\mathrm{Ce}\left(\mathrm{SO}_{4}\right)_{2}$ in that order gave maximum absorbance. The laboratory temperature $\left(25 \pm 5^{\circ} \mathrm{C}\right)$ was found to be optimal for all the experiments. The influence of the reaction time was investigated in the range of $0-20 \mathrm{~min}$. The experimental results show that the final color was achieved with $8 \mathrm{~min}$ and the color product was stable for at least $1200 \mathrm{~min}$ up to $50^{\circ} \mathrm{C}$ and was measured at $566 \mathrm{~nm}$.

The most important factor affecting on the formation of pink product was the concentration of $\mathrm{MBTH}$ and $\mathrm{Ce}\left(\mathrm{SO}_{4}\right)_{2}$. Figure 2 show that a volume of $1.0 \mathrm{~mL}$ of $0.01 \mathrm{M} \mathrm{MBTH}$ solution gave maximum sensitivity. Increasing the volume of MBTH leads to decrease in the absorbance; this may be due to the high background absorbance of the reagent. Also, $1.0 \mathrm{~mL}$ of $1 \% \mathrm{Ce}\left(\mathrm{SO}_{4}\right)_{2}$ was found to be optimal for maximum color development, since the absorbance was found to be maxima at the mentioned volume (Figure 2).

\section{Quantitation methods}

Because the intensity of the color increased with time (Figure 3), this was used as the basis for a useful kinetic method for the determination of atorvastatin. The initial rate, rate constant, variable time (fixed concentration or fixed absorbance) and fixed time methods [29,30] were tested and the most suitable analytical methods were chosen regarding the applicability, sensitivity, the values of the intercept and correlation coefficient $\left(\mathrm{R}^{2}\right)$.

Initial rate method: The initial rate of reaction would follow a pseudo order rate constant and obeyed the following rate equation:

$$
v=\Delta \mathrm{A} / \Delta \mathrm{t}=\mathrm{k}^{\prime} \mathrm{C}^{\mathrm{n}}
$$

Where $v$ is the reaction rate, $\mathrm{A}$ is the absorbance, $\mathrm{t}$ is the measuring time, $\mathrm{k}^{\prime}$ is the pseudo order rate constant, $\mathrm{C}$ is the concentration of the drug $\mathrm{mol} / \mathrm{L}$ and $\mathrm{n}$ is the order of the reaction. A calibration curve was constructed by plotting the logarithm of the initial rate of reaction $(\log v)$ versus logarithm of drug concentration $(\log C)$ which showed a linear relationship over the concentration range of $2-20 \mu \mathrm{g} / \mathrm{mL}$ (Figure 4). The logarithmic form of the above equation is written as follows:

$$
\begin{aligned}
& \log v=\log \Delta \mathrm{A} / \Delta \mathrm{t}=\log \mathrm{k}+\mathrm{n} \log \mathrm{C} \\
& \log v=\log \Delta \mathrm{A} / \Delta \mathrm{t}=1.3291+0.9557 \log [\mathrm{AVS}]\left(\mathrm{R}^{2}=0.9926\right)
\end{aligned}
$$

Thus, $\mathrm{k}=21.335 \mathrm{l} / \mathrm{S}$, and the reaction is the first order $(\mathrm{n}=0.9557)$ with respect to AVS concentration. The limit of detection (LOD) and limit of quantification (LOQ) for initial rate method were determined and were found to be 0.093 and $2.0 \mu \mathrm{g} / \mathrm{mL}$, respectively.

Rate constant method: Graphs of log absorbance versus time for AVS concentration in the range of $2-20 \mu \mathrm{g} / \mathrm{mL}\left(1.65 \times 10^{-6}\right.$ to $1.65 \times 10^{-5}$ $\mathrm{M})$ were plotted and all appeared to be rectilinear. Pseudo order rate constant $(\mathrm{k})$ corresponding to different AVS concentrations were

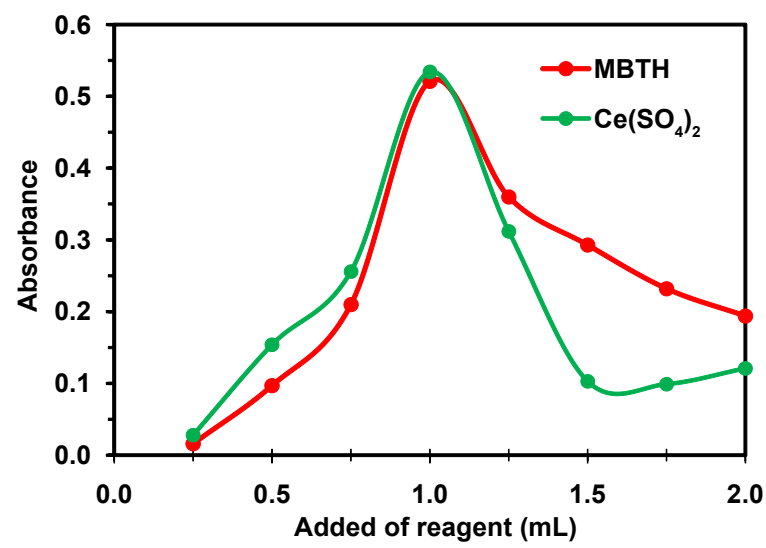

Figure 2: Effect of concentration of MBTH in the presence of $1.0 \mathrm{~mL}$ of $1 \% \mathrm{Ce}\left(\mathrm{SO}_{4}\right)_{2}$ and concentration of $\mathrm{Ce}\left(\mathrm{SO}_{4}\right)_{2}$ in the presence of $1.0 \mathrm{~mL}$ of $10^{-2} \mathrm{M} \mathrm{MBTH}$ on the formation of colored oxidative coupling product AVS $(20 \mu \mathrm{g} / \mathrm{mL})-\mathrm{MBTH}-\mathrm{Ce}\left(\mathrm{SO}_{4}\right)_{2}$.

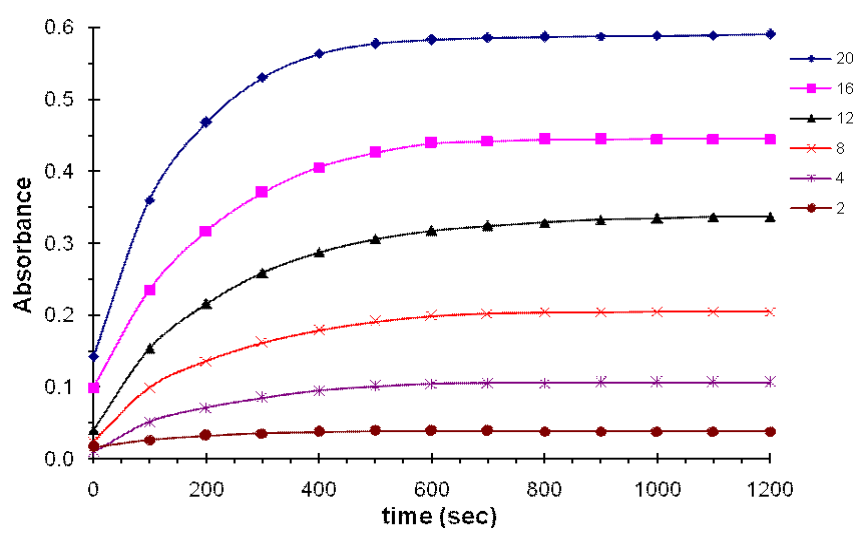

Figure 3: Absorbance-time curve for the reaction of AVS with $M B T H ; C_{A V S}=$ $2-20 \mu \mathrm{g} / \mathrm{mL}$.

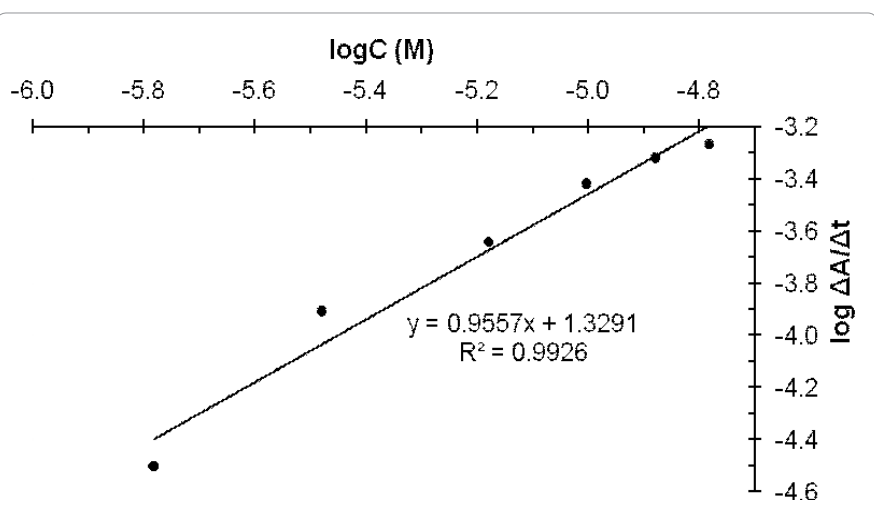

Figure 4: Calibration plot of logarithm rate of the reaction against logarithm molar concentration of AVS for initial rate method.

calculated from the slopes multiplied by -2.303 and are presented in table 1 . Regression of $\mathrm{C}$ versus $\mathrm{k}$ gave the following equation:

$$
\mathrm{k}^{\prime}=47.52 \mathrm{C}-164.9\left(\mathrm{R}^{2}=0.9014\right)
$$


Variable time method: Reaction rate data were recorded for different AVS concentrations in the range $2-20 \mu \mathrm{g} / \mathrm{mL}$. A preselected value of the absorbance 0.30 was fixed and the time was measured in the seconds (Table 2). The reciprocal of time (1/t) versus the initial concentration of AVS was plotted and the following equation of calibration graph was obtained:

$$
1 / t=1175 C-0.016\left(R^{2}=0.9473\right)
$$

The range of AVS concentrations giving the most satisfactory results was limited $12-20 \mu \mathrm{g} / \mathrm{mL}\left(9.92 \times 10^{-6}\right.$ to $\left.1.65 \times 10^{-5} \mathrm{M}\right)$ (Table 2).

Fixed time method: At preselected fixed time, the absorbance of pink colored solution containing varying amounts of AVS was measured at $25^{\circ} \mathrm{C}$ and $566 \mathrm{~nm}$. Calibration graphs were constructed by plotting the absorbance against the initial concentration of AVS at fixed time 200, 400, 600, 800 and $1000 \mathrm{sec}$. The regression equations, correlation coefficients and linear ranges are given in table 3 . Correlation coefficient, intercept and slope values for the calibration data calculated using the least squares method [31].

It is clear that, the slope increases with time and the most acceptable values of the correlation coefficient, linear range and the intercept were obtained for a fixed time of $800 \mathrm{sec}$. Therefore, the fixed time of $800 \mathrm{sec}$ was utilized for the assay of AVS concentration. The limit of detection (LOD) and limit of quantification (LOQ) for fixed time $(800 \mathrm{sec})$ method were determined and were found to be 0.064 and 2.0 $\mu \mathrm{g} / \mathrm{mL}$, respectively. For more accurate analysis, Ringbom optimum concentration range was calculated to be $4.2-15.7 \mu \mathrm{g} / \mathrm{mL}$. Table 4 shows the values of molar absorptivity, Sandell's sensitivity and some analytical characteristics for fixed time $(800 \mathrm{sec})$ method.

\section{Stoichiometric relationship}

The composition of colored oxidative coupling product was determined by Job's method of continuous variation and mole-ratio method [32], for fixed time $(800 \mathrm{sec})$ method. It is apparent from the data that a molar ratio of $1: 1$ and 1:2 AVS to MBTH.

As a result, the most acceptable values of the correlation coefficients were obtained for an initial rate and fixed time $(800 \mathrm{sec})$ methods. Thus, they were used for the determination of AVS in pure form and pharmaceutical formulations.

\section{Analytical methods validation}

The accuracy and precision of the proposed methods were carried out by six determinations at five different concentrations. Percentage relative standard deviation (RSD\%) as precision and percentage relative error (Er\%) as accuracy of the suggested methods was calculated. Table 5 shows the values of relative standard deviations for different concentrations of AVS determined from the calibration curves. These results of accuracy and precision show that the proposed methods have good repeatability and reproducibility. The proposed methods were found to be selective for the estimation of AVS in the presence of various tablet excipients. For this purpose, a powder blend using typical tablet excipients was prepared along with the drug and then analyzed. The recoveries were not affected by the excipients and the excipients blend did not show any absorption in the range of analysis.

\section{Application to the pharmaceutical dosage forms}

The proposed procedure was applied to determine atorvastatin in its pharmaceutical formulations. The results obtained were compared statistically by the student's t-test (for accuracy) and the variance ratio F-test (for precision) with those obtained by the reference method [27] on samples of the same batch (Table 6). Mean values were obtained with a Student's t- and F-tests at 95\% confidence limit for five degrees of freedom [31]. The results showed comparable accuracy (t-test) and precision (F-test), since the calculated values of $t$ - and F-tests were less than the theoretical data indicating no significant difference between the methods compared. The proposed method has the advantages of being virtually free from interferences by excipients such as glucose, lactose, and starch or from common degradation products (Tables 5 and 6).

\section{Conclusion}

The developed kinetic spectrophotometric method for the determination of atorvastatin was sensitive, accurate and precise and hence can be used for the routine analysis of AVS in bulk and pharmaceutical formulations with a limit of detection of $0.064 \mu \mathrm{g} / \mathrm{mL}$. MBTH was used as a reagent in acidic medium. The sample recoveries from all formulations were in good agreement with their respective label claims, which suggested non-interference of formulations excipients in the estimation. The developed method is more speed and

\begin{tabular}{|c|c|}
\hline [AVS] (M) & $\mathbf{k}(\mathbf{1} / \mathbf{S})$ \\
\hline $1.65 \times 10^{-6}$ & 0 \\
\hline $3.30 \times 10^{-6}$ & $-1.44 \times 10^{-3}$ \\
\hline $6.61 \times 10^{-6}$ & $-1.32 \times 10^{-3}$ \\
\hline $9.92 \times 10^{-6}$ & $-1.31 \times 10^{-3}$ \\
\hline $1.32 \times 10^{-5}$ & $-0.94 \times 10^{-3}$ \\
\hline $1.65 \times 10^{-5}$ & $-0.85 \times 10^{-3}$ \\
\hline
\end{tabular}

Table 1: Values of rate constant $\mathrm{K}^{\prime}$.

\begin{tabular}{|c|c|}
\hline [AVS] (M) & $\left.\mathbf{1 / t} \mathbf{( S}^{-1}\right)$ \\
\hline $9.92 \times 10^{-6}$ & 0.00215 \\
\hline $1.32 \times 10^{-5}$ & 0.00562 \\
\hline $1.65 \times 10^{-5}$ & 0.01389 \\
\hline
\end{tabular}

Table 2: Values of reciprocal time taken at fixed absorbance for the different rates of variable concentration of AVS at MBTH constant concentration.

\begin{tabular}{|c|c|c|c|}
\hline Time (sec) & Regression equation & $\begin{array}{c}\text { Correlation } \\
\text { coefficient }\end{array}$ & Linear range $(\mathbf{\mu g} / \mathbf{m L})$ \\
\hline 200 & $\mathrm{~A}=0.023 \mathrm{C}-0.032$ & 0.9742 & $2-20$ \\
\hline 400 & $\mathrm{~A}=0.028 \mathrm{C}-0.031$ & 0.9895 & $2-20$ \\
\hline 600 & $\mathrm{~A}=0.029 \mathrm{C}-0.025$ & 0.9966 & $2-20$ \\
\hline 800 & $\mathrm{~A}=0.029 \mathrm{C}-0.022$ & 0.9998 & $2-20$ \\
\hline 1000 & $\mathrm{~A}=0.029 \mathrm{C}-0.024$ & 0.9969 & $2-20$ \\
\hline
\end{tabular}

A-absorbance; C-concentration

Table 3: Regression equations for AVS at fixed time and $25^{\circ} \mathrm{C}$.

\begin{tabular}{|l|l|}
\hline Parameters & AVS \\
\hline$\lambda_{\max }(\mathrm{nm})$ & 566 \\
\hline Beer's law range $(\mu \mathrm{g} / \mathrm{mL})$ & $2.0-20.0$ \\
\hline Molar absorptivity $(\mathrm{L} / \mathrm{mol} \mathrm{cm})$ & $3.36 \times 10^{4}$ \\
\hline Stability $(\mathrm{min})$ & 1200 \\
\hline Stoichiometric relationship, AVS:MBTH & $1: 1 \quad 1: 2$ \\
\hline Logarithmic formation constants & $5.9 \quad 8.6$ \\
\hline Optimum photometric range $(\mu \mathrm{g} / \mathrm{mL})$ & $4.2-15.7$ \\
\hline Detection limit $(\mu \mathrm{g} / \mathrm{mL})$ & 0.064 \\
\hline Sandell's sensitivity $\left(\mu \mathrm{g} / \mathrm{cm}^{2}\right.$ per 0.001 absorbance unit) & 0.070 \\
\hline Regression equation ${ }^{\mathrm{a}}$ & $\mathrm{A}=0.029 \mathrm{C}-0.022$ \\
\hline Correlation coefficient, $\mathrm{R}^{2}$ & 0.9998 \\
\hline
\end{tabular}

${ }^{a} \mathrm{~A}=\mathrm{mC}+\mathrm{b}$, where $\mathrm{C}$ is the concentration in $\mu \mathrm{g} / \mathrm{mL}$ and $\mathrm{A}$ is the absorbance

Table 4: Analytical characteristics of the fixed time $(800 \mathrm{sec})$ method. 
Citation: Ashour S (2013) New Kinetic Spectrophotometric Method for Determination of Atorvastatin in Pure and Pharmaceutical Dosage Forms. Pharm Anal Acta 4: 232. doi:10.4172/2153-2435.1000232

Page 5 of 6

\begin{tabular}{|c|c|c|c|c|c|}
\hline \multirow{2}{*}{ Method } & \multicolumn{2}{|c|}{ AVS $(\mu \mathrm{g} / \mathrm{mL})$} & \multirow{2}{*}{$\mathrm{Er} \%$} & \multirow{2}{*}{ RSD (\%) } & \multirow{2}{*}{$\%$ Recovery \pm SD } \\
\hline & Taken & Founda & & & \\
\hline \multirow{5}{*}{ Initial rate } & 2.00 & 2.01 & 0.49 & 3.08 & $100.50 \pm 0.32$ \\
\hline & 4.00 & 4.06 & 1.48 & 2.52 & $101.50 \pm 0.41$ \\
\hline & 12.00 & 12.12 & 0.99 & 1.58 & $101.00 \pm 0.36$ \\
\hline & 16.00 & 16.14 & 0.86 & 0.92 & $100.87 \pm 0.30$ \\
\hline & 20.00 & 20.13 & 0.64 & 0.73 & $100.65 \pm 0.29$ \\
\hline \multirow{5}{*}{ Fixed time } & 2.00 & 2.02 & 0.99 & 2.85 & $101.00 \pm 0.30$ \\
\hline & 4.00 & 4.05 & 1.23 & 2.02 & $101.25 \pm 0.27$ \\
\hline & 12.00 & 12.09 & 0.74 & 1.28 & $100.75 \pm 0.33$ \\
\hline & 16.00 & 16.08 & 0.50 & 0.85 & $100.50 \pm 0.28$ \\
\hline & 20.00 & 20.19 & 0.94 & 0.64 & $100.95 \pm 0.21$ \\
\hline
\end{tabular}

Table 5: Accuracy and precision for the determination of AVS in bulk powder by the proposed initial rate and fixed time methods.

\begin{tabular}{|c|c|c|c|}
\hline \multirow{3}{*}{ Sample } & \multicolumn{3}{|c|}{$\%$ Recovery $^{\mathrm{a}} \pm$ SD } \\
\hline & \multicolumn{2}{|c|}{ Proposed methods } & \multirow{2}{*}{ Official method } \\
\hline & Initial rate & Fixed time & \\
\hline \multirow{3}{*}{$\begin{array}{l}\text { Pure AVS } \\
\text { t-value } \\
\text { F-value }\end{array}$} & $100.22 \pm 0.14$ & $100.31 \pm 0.12$ & \multirow{3}{*}{$99.40 \pm 0.17$} \\
\hline & 1.68 & 1.85 & \\
\hline & 1.47 & 2.00 & \\
\hline \multicolumn{4}{|c|}{ Atoraz tablets (20 mg AVS/tablet) } \\
\hline$X \pm$ S.D. ${ }^{a}$ & $100.69 \pm 0.17$ & $100.86 \pm 0.24$ & $100.03 \pm 0.21$ \\
\hline t-value ${ }^{b}$ & 1.72 & 1.07 & 1.85 \\
\hline F-value ${ }^{b}$ & 1.53 & 1.31 & \\
\hline \multicolumn{4}{|c|}{ Low-lip tablets (10 mg AVS/tablet) } \\
\hline$X \pm$ S.D. ${ }^{a}$ & $100.17 \pm 0.23$ & $100.31 \pm 0.29$ & $99.94 \pm 0.25$ \\
\hline t-value ${ }^{b}$ & 1.49 & 1.55 & 1.79 \\
\hline F-value ${ }^{b}$ & 1.18 & 1.34 & \\
\hline \multicolumn{4}{|c|}{ Atorvast tablets (40 mg AVS/tablet) } \\
\hline$X \pm$ S.D. ${ }^{a}$ & $101.07 \pm 0.19$ & $101.17 \pm 0.23$ & $100.93 \pm 0.20$ \\
\hline t-value ${ }^{b}$ & 1.79 & 1.49 & 1.27 \\
\hline F-value $^{b}$ & 1.11 & 1. & 1. \\
\hline \multicolumn{4}{|c|}{ Atorvatin tablets (20 mg AVS/tablet) } \\
\hline$X \pm$ S.D. ${ }^{a}$ & $100.78 \pm 0.21$ & $101.06 \pm 0.31$ & $100.09 \pm 0.26$ \\
\hline t-value ${ }^{b}$ & 2.05 & 1.98 & 1.83 \\
\hline F-value $^{b}$ & 1. & 2.40 & \\
\hline \multicolumn{4}{|c|}{ Atorvex tablets (80 mg AVS/tablet) } \\
\hline$X \pm$ S.D. ${ }^{a}$ & $101.21 \pm 0.24$ & $100.58 \pm 0.21$ & $100.98 \pm 0.26$ \\
\hline t-value ${ }^{b}$ & 1.76 & 2.05 & 1.86 \\
\hline F-value ${ }^{b}$ & 1.17 & 1.53 & \\
\hline \multicolumn{4}{|c|}{ Lipolysin tablets (20 mg AVS/tablet) } \\
\hline$X \pm$ S.D. ${ }^{a}$ & $100.04 \pm 0.12$ & $100.24 \pm 0.17$ & $100.11 \pm 0.14$ \\
\hline t-value ${ }^{b}$ & 1.28 & 0.96 & 1.35 \\
\hline F-value ${ }^{b}$ & 1.36 & 1.47 & \\
\hline
\end{tabular}

aFive independent analyses.

${ }^{b}$ Theoretical values for $t$ and $F$-values at five degree of freedom and 95\% confidence limit are $(t=2.776)$ and $(F=6.26)$.

Table 6: Application of the proposed method to the determination of AVS in tablet dosage form.

higher sensitivity as compared to sophisticated spectrophotometric techniques and similar reported methods and has a wider range of linearity. Moreover, the lower reagents consumption along with the short analytical run time of 8 min leads to an environmentally friendly spectrophotometric procedure, which makes it especially suitable for routine quality control analysis work.

\section{References}

1. Shitara $Y$, Sugiyama $Y$ (2006) Pharmacokinetic and pharmacodynamic alterations of 3-hydroxy-3-methylglutaryl coenzyme A (HMG-CoA) reductase inhibitors: drug-drug interactions and interindividual differences in transporter and metabolic enzyme functions. Pharmacol Ther 112: 71-105.
2. Li WL, Zhong QY, Wen Q (2007) HPLC determination of content of atorvastatin calcium capsules and its related substances. Chinese Journal of Pharmaceutical Sciences.

3. Nováková L, Šatínskýa D, Solicha P (2008) HPLC methods for the determination of simvastatin and atorvastatin. Tr AC Trends in Analytical Chemistry 27: 352367.

4. Erturk S, Aktas ES, Ersoy L, Ficicioglu S (2003) An HPLC method for the determination of atorvastatin and its impurities in bulk drug and tablets. $J$ Pharm Biomed Anal 33: 1017-1023.

5. Petkovska R, Cornett C, Dimitrovska A (2008) Development and validation of rapid resolution RP-HPLC method for simultaneous determination of atorvastatin and related compounds by use of chemometrics. Analytical Letters 41: 992-1009. 
Citation: Ashour S (2013) New Kinetic Spectrophotometric Method for Determination of Atorvastatin in Pure and Pharmaceutical Dosage Forms. Pharm Anal Acta 4: 232. doi:10.4172/2153-2435.1000232

6. Altuntas TG, Erk N (2004) Liquid chromatographic determination of atorvastatin in bulk drug, tablets and human plasma. Journal of Liquid Chromatography \& Related Technologies 27: 83-93.

7. Pasha MK, Muzeeb S, Basha SJ, Shashikumar D, Mullangi R, et al. (2006) Analysis of five HMG-CoA reductase inhibitors- atorvastatin, lovastatin, pravastatin, rosuvastatin and simvastatin: pharmacological, pharmacokinetic and analytical overview and development of a new method for use in pharmaceutical formulations analysis and in vitro metabolism studies. Biomed Chromatogr 20: 282-293.

8. Sonawane SS, Shirkhedkar AA, Fursule RA, Surana SJ (2006) Application of UV-spectrophotometry and RP-HPLC for simultaneous determination of atorvastatin calcium and ezetimibe in pharmaceutical dosage form. Eurasian Journal of Analytical Chemistry 1: 31-41.

9. Shah DA, Bhatt KK, Mehta RS, Shankar MB, Baldania SL, et al. (2007) Development and validation of a RP-HPLC method for determination of atorvastatin calcium and aspirin in a capsule dosage form. Indian Journal of Pharmaceutical Sciences 69: 546-549.

10. Mohammadi A, Rezanour N, Dogaheh MA, Bidkorbeh FG, Hashem M, et al. (2007) A stability-indicating high performance liquid chromatographic (HPLC) assay for the simultaneous determination of atorvastatin and amlodipine in commercial tablets. J Chromatogr B Analyt Technol Biomed Life Sci 846: 215 221.

11. Raja Rajeswari K, Sankar GG, Rao AL, Seshagirirao JVLN (2006) RP-HPLC method for the simultaneous determination of atorvastatin and amlodipine in tablet dosage form. Indian Journal of Pharmaceutical Sciences 68: 275-277.

12. Kumar Talluri MVN, Kalyankar A, Ragampeta S (2012) Synchronized separation of atorvastatin-an antihyperlipidemic drug with antihypertensive, antidiabetic, antithrombotic drugs by RP-LC for determination in combined formulations. Journal of Pharmaceutical Analysis 2: 285-292.

13. U Seshachalam U, Kothapally Chandrasekhar B (2008) HPLC analysis for simultaneous determination of atorvastatin and ezetimibe in pharmaceutical formulations. Journal of Liquid Chromatography \& Related Technologies 31 : 714-721.

14. Nakarani NV, Bhatt KK, Patel RD, Bhatt HS (2007) Estimation of atorvastatin calcium and fenofibrate in tablets by derivative spectrophotometry and liquid chromatography. J AOAC Int 90: 700-705.

15. Chaudhari BG, Patel NM, Shah PB, Patel LJ, Patel VP (2007) Stability-indicating reversed-phase liquid chromatographic method for simultaneous determination of atorvastatin and ezetimibe from their combination drug products. J AOAC Int 90: 1539-1546.

16. Kadav AA, Vora DN (2008) Stability indicating UPLC method for simultaneous determination of atorvastatin, fenofibrate and their degradation products in tablets. J Pharm Biomed Anal 48: 120-126.
17. Jamshid A, Nateghi AR (2007) HPTLC determination of atorvastatin in plasma. Chromatographia 65: 763-766.

18. Erk N (2004) Development of electrochemical methods for determination of atorvastatin and analytical application to pharmaceutical products and spiked human plasma. Critical Reviews in Analytical Chemistry 34: 1-7.

19. Korany MA, Hewala II, Abdel-Hay KM (2008) Determination of etofibrate fenofibrate, and atorvastatin in pharmaceutical preparations and plasma using differential pulse polarographic and square wave voltammetric techniques. J AOAC Int 91: 1051-1058.

20. Al-Shehri MM (2012) A validated capillary electrophoresis method for simultaneous determination of ezetimibe and atorvastatin in pharmaceutical formulations. Saudi Pharmaceutical Journal 20: 143-148.

21. Sharaf El-Din MMK, Salama FMM, Nassar MWI, Attia KAM, Kaddah MMY (2012) Validated spectrofluorimetric method for the determination of atorvastatin in pharmaceutical preparations. Journal of Pharmaceutical Analysis 2: 200-205.

22. Khan MR, Deepti J (2006) Simultaneous spectrophotometric determination of atorvastatin calcium and amlodipine besylate in tablets. Indian Journal of Pharmaceutical Sciences 68: 546-548.

23. Stanisz B, Rafa W (2008) Development and validation of UV derivative spectrophotometric method for determination of atorvastatin in tablets. Chemia Analityczna 53: 417-428.

24. Erk N (2003) Extractive spectrophotometric determination of atorvastatin in bulk and pharmaceutical formulations. Analytical Letters 36: 2699-2711.

25. Nagaraj, Vipul K, Rajshree M (2007) Simultaneous quantitative resolution of atorvastatin calcium and fenofibrate in pharmaceutical preparation by using derivative ratio spectrophotometry and chemometric calibrations. Anal Sci 23 445-451.

26. Ashour S, Khateeb M (2011) A novel use of oxidative coupling reactions for determination of some statins (cholesterol-lowering drugs) in pharmaceutical formulations. Spectrochim Acta A Mol Biomol Spectrosc 78: 913-917.

27. The British Pharmacopœia (2010) The Stationary Office, vol 2, London.

28. Perez-Bendito D, Gomez-Hens A, Silva M (1996) Advances in drug analysis by kinetic methods. J Pharm Biomed Anal 14: 917-930.

29. Kopanica M, Satra V, Echschlager K, Rorsak I, Koduys Z, et al. (Eds) (1983) Kinetic methods in chemical analysis, Elsevier, Amsterdam, The Netherlands 25-27.

30. Persez-Bendit D, Silva M (1988) Kinetic methods in analytical chemistry, John Wiley and sons, New York, Chap 11: 44-45.

31. Miller JC, Miller JN (1993) Statistics in Analytical Chemistry (3rdedn.) Ellis Horwood, Chichester.

32. Rose J (1964) Advanced Physico-chemical Experiments, Pittman, London, 54 